\title{
PATTERNS OF PRESCRIPTION OF PRIVATE PRACTITIONERS IN BANGLADESH
}

\author{
ZAHAN T ${ }^{1}$, PROF. BHUIYAN MM ${ }^{2}$, KHAN MI ${ }^{3}$
}

\begin{abstract}
:
A prescription - a written instruction of doctors to pharmacist to supply drugs in particular form to a patient and the directions to the patients regarding the use of medicines. This study was undertaken to observe the prescribing patterns of the practitioners in Bangladesh, 500 prescriptions were collected randomly from Dhaka city and analyzed using WHO/INRUD indicators. There were average 4.40drugs per prescription.Drugs were prescribed in generic name only in $0.30 \%$. About $48 \%$ drugs were prescribed from the essential drug list, only prescriptions were complete. In respect to patient medication information, antibiotics were prescribed in $72 \%$ of the prescriptions; injections were prescribed in about $10 \%$ of the prescriptions.
\end{abstract}

Keywords: Prescription pattern, private practitioners

J Dhaka Med Coll. 2017; 26(1) : 48-51

\section{Introduction:}

Prescription writing is a science and art, as it carries the message from the prescriber to the patient. ${ }^{1} \mathrm{~A}$ prescription order is a written instruction of doctors to pharmacist to supply drugs in particular form to a patient and the directions to the patients regarding the use of medicines. It is important therapeutic translation between the clinician and the patient ${ }^{2}$.Prescribing is a complex tusk requiring diagnostic skills, knowledge of medicines, an understanding of the principles of clinical pharmacology, communication skills, appreciation of risk and uncertainity ${ }^{3}$. Prescribers can only treat patients in a rational way if they go through an essential drugs list and essential drugs are available on a regular basis ${ }^{4}$.

Irrational use of medicines is a global problem, particularly in developing and translational countries.Country like Bangladesh, irrational prescribingis common finding. Frequently observed irrational use of medicines per patient(poly pharmacy), inappropriate use of antimicrobials, over use of injections and vitamins. On the other hand, aggressive drug marketing, lack of information on the use of drug and inadequate drug supply has been suggested to be the main causes behind the irrational prescribing. ${ }^{5}$ Irrational drug use leads to reduce in the quality of drug therapy, excess treatment cost, increased risk for adverse reactions and emergence of resistance ${ }^{6}$. The prescribed drug costs a huge money, causing problems in developing country like Bangladesh. This problem can be solved by prescribing drug by generic name and it should be selected from essential drug list. Generic drugs are substitute of brand drug without any patent protections having similar efficacy though 40-60\% cheaper than brand drug ${ }^{7}$.

Doctors are bound to prescribe easily available, affordable and essential medicines to the patients; rather they are blamed to prescribe costly branded drugs ${ }^{8}$. Changing the bad practicing habits is a must. Prescription audit is another approach to avoid irrational prescribing. Periodic evaluation of prescribing

1. Dr. Tahmina Zahan, Assistant Professor, Dept. of Pharmacology, Holy Family Red Crescent Medical College,

2. Prof. Dr. Md. Maniruzzaman Bhuiyan, Professor and Head, Department of Paediatrics and NICU Holy Family Red Crescent Medical College

3. Prof. Dr. Md. Ismail Khan, Professor and Head, Department of Pharmacology, Dhaka Medical College Correspondence: Dr. Tahmina Zahan, Assistant Professor, Dept. of Pharmacology, Holy Family Red Crescent Medical College, Mob: 01700602469; email: tahminazahan@yahoo.com

Received: 23 December 2016

Accepted: 01 March 2017 
pattern leads to increase therapeutic efficacy, decrease adverse effects and provide feedback to prescribers. ${ }^{9,10,11}$ Irrational and inappropriate use of drugs is very common in Bangladesh. International network of rational Use of drugs (INRUD) has developed a list of indicators of rational prescribing. ${ }^{12}$ Thus, this study was an attempt to evaluate the prescribing patterns of the private practitioners in Bangladesh.

\section{Materials and methods:}

Samples of prescription of private practitioners were collected from patients randomly. Mode of collection was copying of prescriptions by photocopy or by digital camera. Patients consent was taken. All the prescriptions were analyzed according to INRUD indicators. Following parameters were analyzed-

1. Average number of drugs per prescription

2. Percentage of drugs prescribed by generic name

3. Percentage of prescriptions with an antibiotic prescribed

4. Percentage of prescriptions with an injection prescribed

5. Percentage of drug prescribed from essential drug list

6. Whether prescription is complete with respect to-

a. Format

b. Dosage and duration

c. Patient medical information

The sum total of average and percentages were calculated by using standard formulas in WHO's manual on "How to investigate drug use in health facilities" 11 .

\section{Results:}

Total 2200 drugs were prescribed in all prescriptions. Average drugs per prescriptions $4.40 \%$. Only $0.30 \%$ of drugs were prescribed in generic name. Antibiotics constituted $72 \%$ of prescriptions. Injections were prescribed in about $10 \%$ of prescriptions. About $48 \%$ drugs were prescribed from essential drug list. Only $23 \%$ of prescriptions were complete in respect to patient medical information.
Table-I

Results of prescription audit $(n=500)$

\begin{tabular}{lc}
\hline Prescribing indicator & Results \\
\hline $\begin{array}{l}\text { Average number of drugs } \\
\text { per prescription }\end{array}$ & $4.40 \%$ \\
$\begin{array}{l}\text { Percentage of drugs prescribed } \\
\text { by generic name }\end{array}$ & $0.30 \%$ \\
$\begin{array}{l}\text { Percentage of prescriptions with } \\
\text { an antibiotic prescribed }\end{array}$ & $72 \%$ \\
$\begin{array}{l}\text { Percentage of prescriptions with } \\
\text { an injection prescribed }\end{array}$ & $10 \%$ \\
$\begin{array}{l}\text { Percentage of prescriptions with an } \\
\text { injection prescribedPercentage }\end{array}$ & $48 \%$ \\
of drug prescribed from essential & \\
drug list & \\
Whether prescription is complete with respect \\
to- \\
$\begin{array}{l}\text { d. Format } \\
\text { e. Dosage and duration }\end{array}$ \\
\begin{tabular}{l} 
f. Patient medical information \\
\hline
\end{tabular}
\end{tabular}

\section{Discussion:}

This study attempted to find the pattern of prescription writing among private practitioners in Dhaka city. Out of 500 prescriptions, data were analyzed by applying some of the INRUD indicators. In our study, on an average 4.40 drugs were prescribed per prescription, which was 3.81 in a study conducted in 2009 and 3.24 in another study conducted in 2001 and 3.40 in another study in 2012 13,14,16. In an Indian study, the average number of drugs per case was $3.12^{8}$. In our study most of the private practitioners violated the criteria of rational prescribing.

In a study, Paul et al., and Alam et al., showed that drugs were prescribed in generic name $0.013 \%$ and $1.33 \%$ respectively 14,15 . But in our study, $0.30 \%$ drugs were prescribed by generic name. In an Indian study it was $4.24 \%$, $44 \%$ in study conducted in Nepal 8,16 . The lowest value was $0.008 \%{ }^{13}$ and $0.20 \%$ in a study done in our country ${ }^{13,117}$. This indicates that the prescribers are not aware of the importance of generic name. 
In this study $72 \%$ prescriptions were prescribed with antimicrobials. This finding is quite similar with the study Rahman $Z$ et $\mathrm{al}^{13}$ where the result was $72.50 \%$. Baqui and Chudhury ${ }^{18}$ also reported that percentage of prescriptions with antimicrobials were $73.33 \%$, while Paul et al and Rahman et al found it to be $36.83 \%{ }^{14}$ and $38.7 \% 18$ respectively. In the present study, about $48 \%$ of the drugs were prescribed from the Essential Drug List. Paul et al and Baqui and Choudhury have reported that respectively $48.35 \%$ and $49 \%$ of prescribed medicines were from $\mathrm{EDL}^{14,18}$. About $10 \%$ prescriptions contained an injection which was almost similar with the study done by Saurabh et al $(8.0)^{8}$ and $8.35 \%$ in the study done by Begum $\mathrm{F}$ et al. (2012). But in comparison it was more $(12.1 \%)$ in the study of Rahman $Z$ et $\mathrm{al}^{13}$. About $74 \%$ prescriptions were provided with proper instructions regarding drug dosing, formulation and duration, which was $70 \%$ in the study of Rahmaul $\mathrm{Z}$ et al ${ }^{13}$, while Baqui and Choudhury ${ }^{18}$, found it $58 \%$. On the other hand, only $19 \%$ prescriptions contained proper instructions about patient medication information and advice like side effects of the prescribed drugs, other relevant advice and follow up of the patients. This patient medication information parameter was $17.5 \%$ in the study Rahman $Z$ et $\mathrm{al}^{13}$ and $35.68 \%$ prescriptions follow the proper instructions about prescription format. On the other hand, our study revealed that hand writing was illegible in one third of prescriptions. The illegibility (unclear hand writing) of prescriptions could result in misinterpretation and mistakes ${ }^{20}$.

From this study it was revealed that prescribing pattern of the private practitioners were irrational regarding polypharmacy, generic name, use of antibiotics, drug selection from EDL and provide information. Irrational prescribing is tough to cure from the root. But it can be prevented. Proper training in pharmacotherapy and workshop on rational use of drugs may improve prescription behavior and skills $^{21,22}$. Strict rules should be implemented by the Government to ensure rational prescribing.

\section{References:}

1. Kumari R, Idris MZ, Bhushan V, Khanna A, Ararwal A, Sing SK.Assessment of prescription pattern at the public health facilities of Lucknow district . Indian J Pharmacol 2008; 40(6):243247.

2. Ansari KU, Singh S, Pandey RC.Evaluation of prescribing pattern of doctors for drug therapy. Indian J Pharmacol 1998; 30: 43-46.

3. Khan MI, Ara N. Promoting rational prescribing among medical practioners. Bangladesh Med Journal 2011; 40(2): 6-7.

4. World Health Organization (WHO). International Network for Rational use of Drugs and World Health organization. How to investigate drug use in health facilities. Selected drug use indicators 1993. EDM Research Series No. 7(WHO/DAP/ 93.1)

5. Offerhaus. Rational use of drugs in Balkans: a WHO workshop. Essential Drugs Monitor 1995; 20:3.

6. Bhartie SS, Shinde M, Nadeshwar S, Tiwari SC. Pattern of prescribing practices in the Madhya Pradesh, india. Kathmandu Univ Med J. 2008; 6: 55-59.

7. Sharma PC, Kumar S, Phawa A, Sharma R. Opprtunities for Generic Drugs in India. The internet Journal of Third World Medicine 2009;8.

8. Saurabh MK, Yadav AK, Gupta P, Singhai A, Saurabh A. Comparative study of prescribing behaviors of government doctors of teaching hospital and private practitioners in Jhalawar City (Rajasthan). J. Pharm. Sci. \& Res. 2010; 2(4):20815.

9. Akici A, Gören MZ, Aypak C, Terziog1lu B, Oktay S. Prescription audit adjunct to rational pharmacotherapy education improves prescribing skills of medical students. Eur J Clin Pharmacol. 2005; 61(9):643-50.

10. Krishnaswamy K, Dinesh KB, Radhaiah G. A drug use surveyprecepts and practices. Eur J Clin Pharmacol. 1985; 25:363-70.

11. Pradhan SC, Shewade DG, Shashindran $\mathrm{CH}$, Bapna JS. Drug utilization studies. National Med J India 1988; 1:185-89.

12. How to investigate drug use in health facilities: selected drug use indicators, Geneva, World Health Organization, 1993.

13. Rahman Z, Nazneen R, Begum M. Evaluation of prescribing pattern of the private practitioners by the undergraduate medical students. Bangladesh J Pharmacol. 2009; 4:73-5. 
14. Paul PC, Pal DR, Rahman MM, Islam MJ, Siddique AR. Evaluation of prescribing practices in outpatient department of teaching hospital. BMJ 2011; 40(2):19-22.

15. Alam MM, Parveen F, Ara F, Iqbal MJU, Saha RR. Prescribing trends in the out patient department in a tertiary hospital in Bangladesh. Bangladesh Med Journal 2011; 40(2):8-12.

16. Kafle KK and members of Inrud Nepal Core Group. Inrud drug use indicators in Nepal: Practice patterns in health posts in four districts. INRUD News 1992; 3(1):15.

17. Begum F, Uddin R, Shahin-U1-Islam M.M., Sharker N, Barman RC, Ali Y. Evaluation of Prescribing Pattern of the Private Practitioners in Bangladesh. Faridpur Med. Coll. J. 2012; $7(2): 51-53$

18. Baqui QBOF, Choudhury SAR. Prescribing pattern of graduate and non-graduate medical prescribers in rural Bangladesh. International Conferences on Improving Use of Medicines, 1996.

19. Rahman MS, Begum M, Khan IA, Kamal ASMA, Choudhury S, Islam AMZ, Sultana $R$ et al. A baseline survey on use of drugs at private practitioner level in Bangladesh. Bangladesh $\mathrm{J}$ Physiol Pharmacol. 1998; 14:47-50.

20. WHO/DAP. Guide to Good prescribing Geneva, 1994; 62.

21. Vries De TP, Henning RH, Hogerzeil HV, Bapna JS, Bero L, Kafle KK. Impact of a short course in pharmacotherapy for undergraduate medical students: An international randomized controlled study. Lancet. 1995; 346:1454-7.

22. Thomas M, Cherian AM, Mathai D. Measuring the impact of focused workshops on rational drug use. Trop Doct. 1997; 27:206-10. Faridpur Medical College Journal Vol. 7, No. 2, July 2012. 